\title{
Study on ventilation and noise reduction in the main transformer room in indoor substation
}

\author{
Sheng $\mathrm{Hu}^{\mathrm{a}}$, Shao Yi Chen and Tie Nan Li \\ State Grid Hunan Electric Power Corporation Research Institute, 410007Changsha, Hunan Province, China
}

\begin{abstract}
The noise emission should be considered in the ventilation and cooling design for the main transformer room of indoor substation. In this study, based on Soundplan software, effects of four common ventilation and cooling schemes on the cooling and sound insulation were compared. The research showed that the region with low noise requirement, the ventilation could be set on the outer wall or on the door of the main transformer room, while the region with high noise requirement, air inlet muffler or ventilation through the cable interlayer under the main transformer room must be used. All of the four kinds of ventilation schemes, ventilation through the cable interlayer is the best in cooling and noise reduction.
\end{abstract}

\section{Introduction}

The transformer noise is one of main causes that the substation boundary noise exceeded the environment standard ${ }^{[1]}$. Compared with the outdoor-transformer substation, for indoor-transformer substation, the influence of the substation noise to the surrounding environment can be reduced because the spreading of noise could be better controlled. However, air inlets and outlets have to be set in the main transfermer rooms which cannot be full closed because there is a need of ventilation to cool the heat generated during the operation of transformers.

Currently, there's no perfect solution to consider the mutual effects between the ventilation and noise controlling for the substation, leading to unreasonable set of the air inlets and outlets and overproof noise spread of the ourdoor-transformer substation ${ }^{[2]}$. In this study, effects of four common ventilation and cooling schemes on the cooling and sound insulation effects are compared and analyzed, which will provide a good reference for future noise reduction design in the indoor substation.

\section{Theoretical ventilation calculation}

The ventitation temperature in the transformer room in the summer should not be higher than $45{ }^{\circ} \mathrm{C}^{[3]}$. Not only air exchange rate, but also power loss of the main transformer should be considered in the main transformer room. Generally the power loss of transformer around is $1-3 \%$ and for some fine-making ones, it could be $1 \%$ or even less. In South China, the highest monthly average temperature in summer is about $34{ }^{\circ} \mathrm{C}$ and the indoor temperature in the transformer room is about $45{ }^{\circ} \mathrm{C}$.
Generally speaking, the air flow rate calculated according to the heat generation is greater than that by air exchange rate. Accordingly, the air flow rate should be calculated by the heat generation multiplied by a margin coefficient.

The calculating method of the ventilation rate in the transformer room is as follows ${ }^{[4]}$ :

$$
V=\frac{3600 Q}{\left(t_{n}-t_{w}\right) C \rho}
$$

In which,

$\mathrm{V}$ is the air flow rate, $\mathrm{m}^{3} / \mathrm{h}$;

Q is heat, $\mathrm{kW} .200 \mathrm{~kW}$, according to Table 2;

$\mathrm{P}$ is air density, $\mathrm{kg} / \mathrm{m}^{3}$, generally 1.11 ;

$\mathrm{C}$ is the specific heat of air, $\mathrm{kJ} /(\mathrm{kg} . \mathrm{K})$, generally 1 ;

tn is the maximum permissible temperature indoors..$^{\circ} \mathrm{C}$

tw is the local ventilation temperature outdoors. ${ }^{\circ} \mathrm{C}$

\section{The simulation model of the main transformer room}

\subsection{The physical and acoustic parameters}

The model of the main transformer room is $10 \mathrm{~m} \times$ $10 \mathrm{~m} \times 10 \mathrm{~m}$, and the door is $6 \mathrm{~m} \times 5 \mathrm{~m}$. The cable interlayer under the main transformer room is $10 \mathrm{~m} \times 10 \mathrm{~m}$ $\times 3 \mathrm{~m}$, which is $1.5 \mathrm{~m}$ deeper than surface ground The sound power of the transformer is $80 \mathrm{~dB}(\mathrm{~A})$, which is $5 \mathrm{~m}$ $\times 5 \mathrm{~m} \times 5 \mathrm{~m}$. The transformer in the main transformer room was simplified as five area noise sources. The Sound Transmission Loss of the door is $15 \mathrm{~dB}(\mathrm{~A})$. The noise elimination dose of the Silencing shutter is $5 \mathrm{~dB}(\mathrm{~A})$. The noise elimination dose of the muffler is $20 \mathrm{~dB}(\mathrm{~A})$.

\footnotetext{
${ }^{\mathrm{a}}$ Sheng Hu: hbhusheng@163.com
} 


\subsection{The model based on Soundplan software}

As shown in Fig. 1, the model of four ventilationcooling systems were build based on Soundplan software.

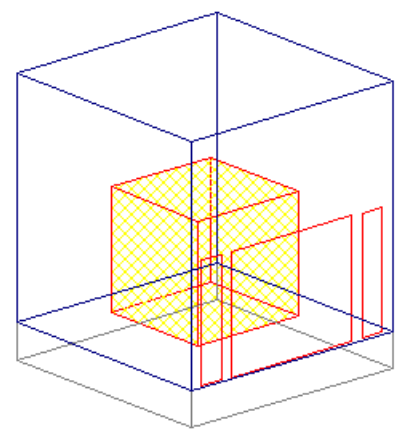

Figure 1. The simulation model of the main transformer room

\section{Design of the ventilation and noise reduction system}

Design of ventilation-cooling system is not only for organization of cooling air flow to ensure an appropriate ventilation rate, but also for sound insulation and noise reduction. At present natural ventilation and mechanical ventilation are employed in indoor type substations. In order to ensure the ventilation effect and efficiency of the fans, generally the natural ventilation velocity should not be greater than $5 \mathrm{~m} / \mathrm{s}$ and low noise fans should be used in mechanical ventilation.

\subsection{Design of cold air inlets}

\subsubsection{Air inlets set in the outer walls of the main transformer room}

Shutter as the air inlet in the outer walls of the main transformer room is a relatively simple design. As shown in Fig. 2 and Fig. 3, the gate of the main transformer room is sound proof and intake silencing shutters are used in the outer walls of both sides of the door. The width of the shutter is in the range of 100-200 mm. Adequate ventilation area could be provided in this design, but sound insulation of the shutter is relatively small, especially for those transformers with low frequency. The sound transmission loss is smaller than 10 $\mathrm{dB}$, therefore the design is applicable only to areas with low noise requirement.

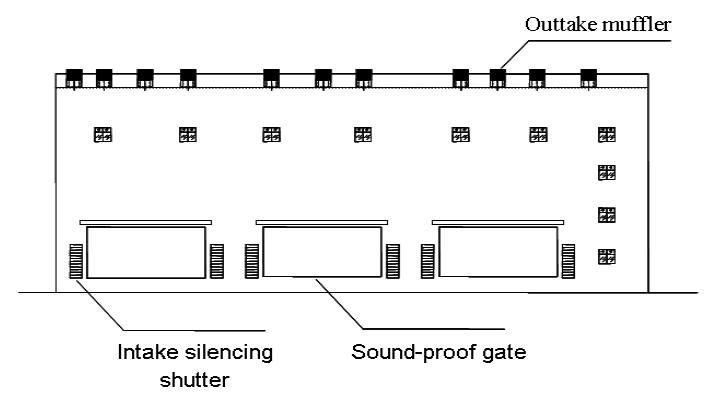

Figure 2. Schematic of the shutter on the outer wall of the main transformer room

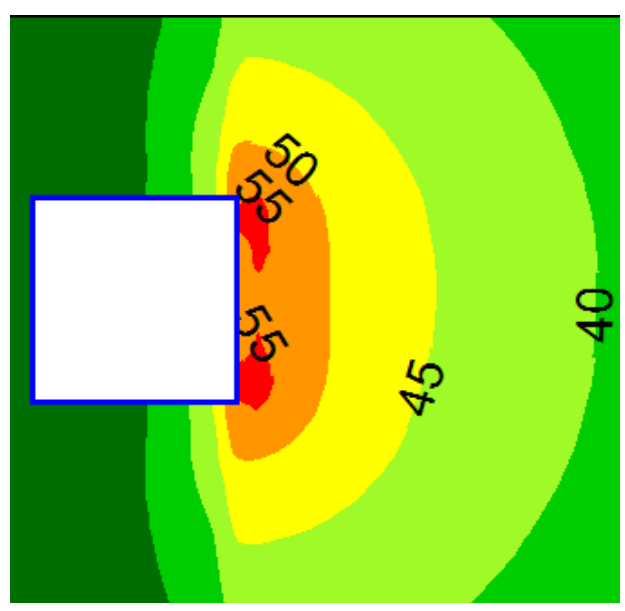

(a)

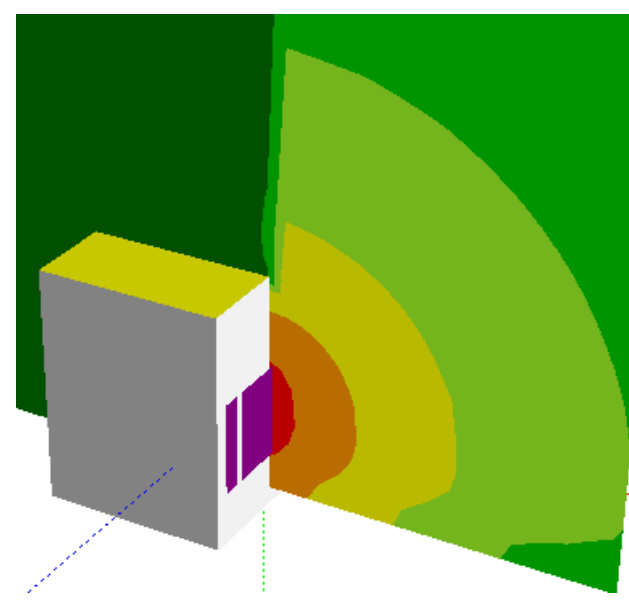

(b)

Fig.3 Sound field distribution of the inlets in the outer wall of the main transformer

\subsubsection{Inlets set on the gate}

Sound-proof gate with intake silencing shutters is also a common ventilation design. As shown in Fig. 4 and Fig. 5, four sound-proof gates of the main transformer room are two-way open and a certain area of silencing shutter is set below each door. The width of the shutter is consistent with the thickness of the soundproof gate. For this design the civil construction load could be saved and it is convenient to construction. Due to the limitation of the soundproof gates, the inlets area and with of the shutters are limited and the sound transmission loss is generally lower than $15 \mathrm{db}$.

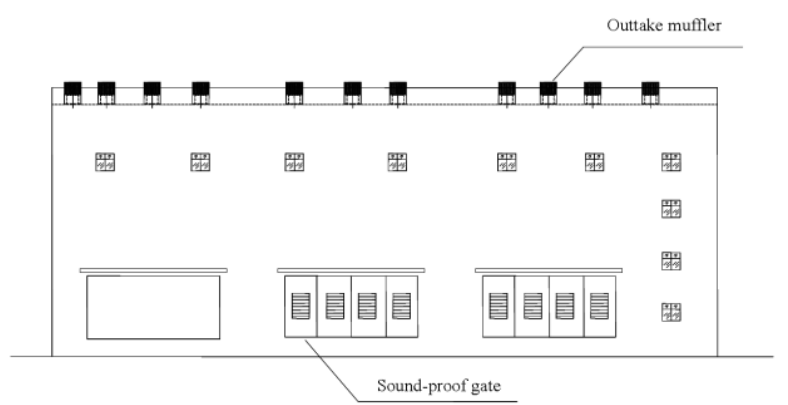

Figure 4. Schematic of the inlets on the gate of main transformer room 


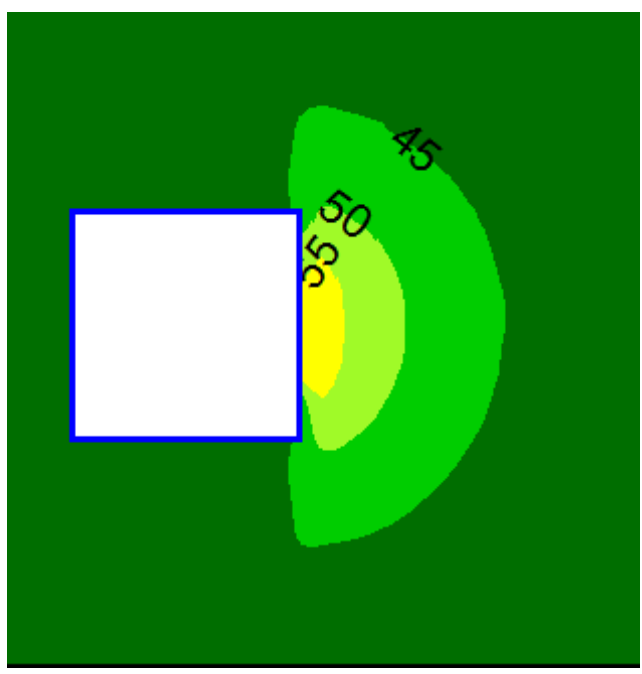

(a)

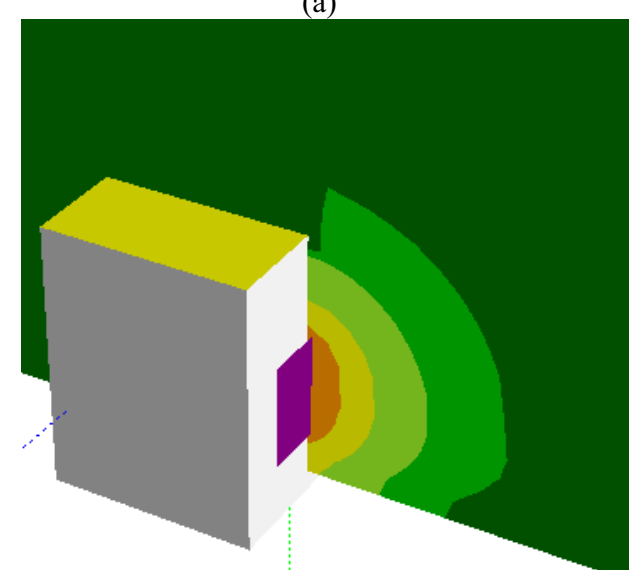

(b)

Fig. 5 Sound field distribution of the inlets in the outer wall of the main transformer

\subsubsection{The intake muffler}

Intake mufflers are set in case of high moise requirement which cannot be satisfied with silencing shutters. As shown in Fig. 6 and Fig. 7, intake mufflers are set at the bottom of the outer wall of the main transformer room. The noise reducing effects are well related with the length of the muffle when the circumference and the area of the muffle is limited. The sound transmission loss of this scheme is up to $20-30 \mathrm{~dB}$. However, the size of the muffler is relatively big and the muffler will take up more space, which would influence the overall appearance.

\subsubsection{Ventilation through the lower cable interlayer of the main transformer room}

As shown in Fig. 8 and Fig. 9, the advantages of ventilation through the lower cable interlayer of the main transformer room are, (1) The noise would not be spread outdoors through ventilation holes, for the noise source is not directly facing the inlet;(2)The cooling effect is good, for the cold air is flowing into indoor through the bottom of the room, forming a natrual convection and a reasonable air distribution. (3)No extra space would be taken up and it has a good appearance.

The sound transmission loss of this scheme is up to 20-30 dB. However, it should be applied in the initial construction stage of the transformer substation and it's hard to rebuild once the construction is finished, because of the stress issue, the fire safety and rain-proof.

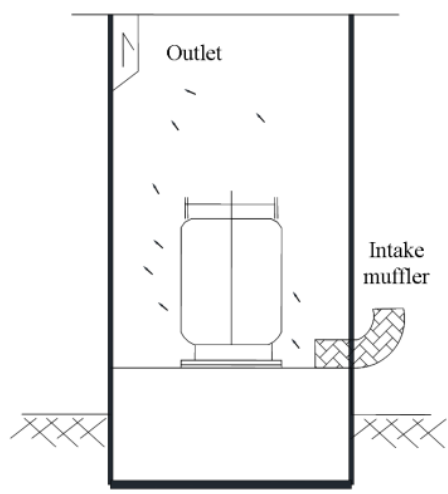

Figure 6. Schematic of the inlets on the gate of main transformer room

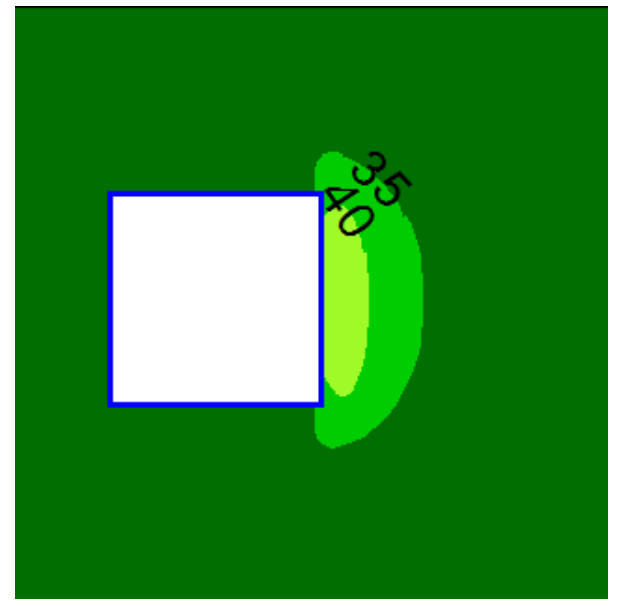

(a)

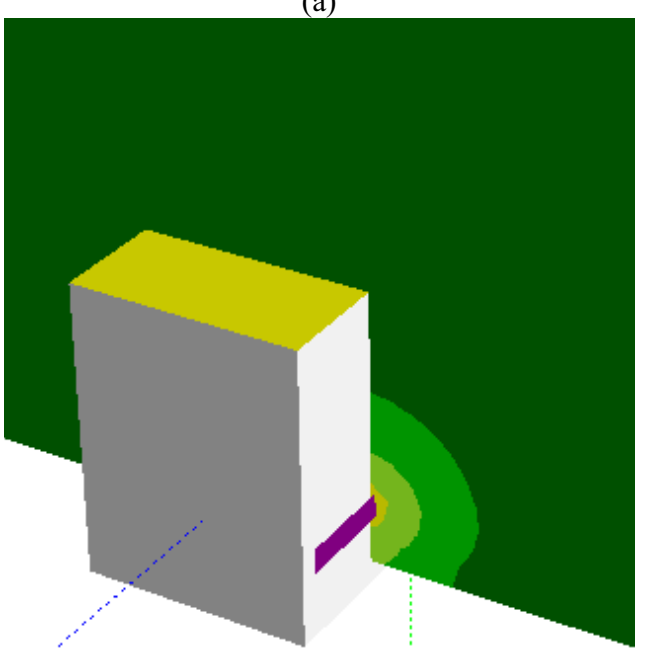

(b)

Figure 7. Sound field distribution of the inlets in the outer wall of the main transformer 


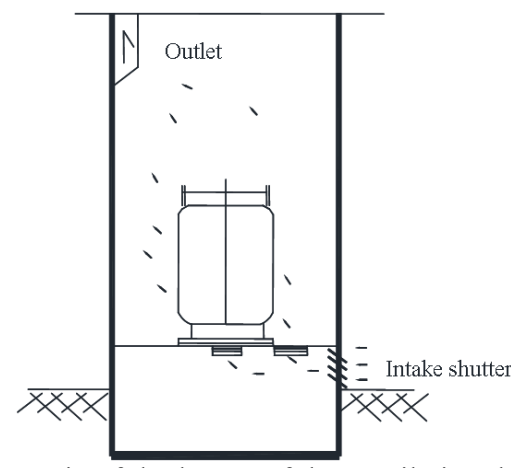

Figure 8. Schematic of the layout of the ventilation through the lower cable interlayer of the main transformer room

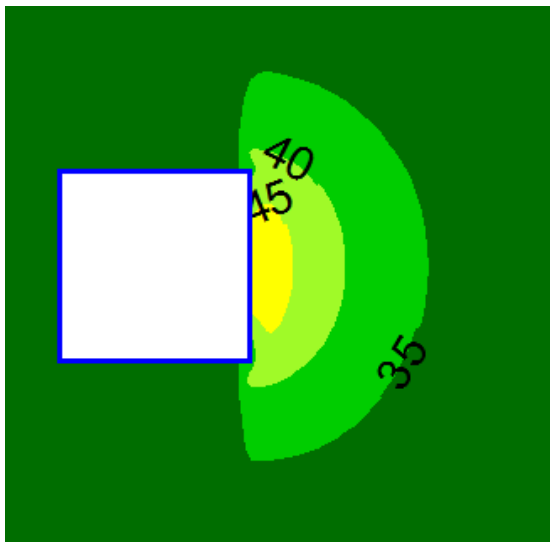

(a)

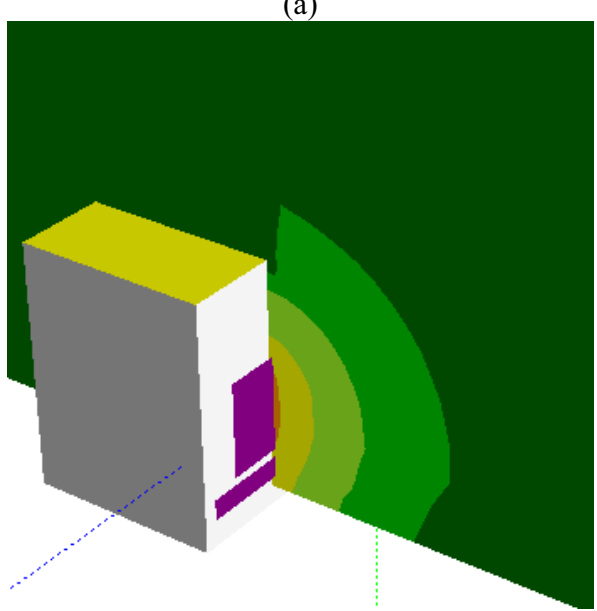

Figure 9. Sound field distribution of the inlets in the outer wall of the main transformer

\subsection{Design of hot air outlets}

Generally ventilation holes are set in the upper part of roof of the main transformer room, connected with the fans discharging hot air. The air volume of the fan should be greater than the calculated theoretical ventilation cooling capacity. Automatic control of the fan can be employed, so that when the temperature in the main transformer room exceeds the preset temperature the fan would automatically run. In ordinary cases cooling can be achieved by natural ventilation, which can save energy and reduce emissions. Considering the effects of fan noise, muffler can be added or fan room could be used in the design to reduce the fan noise.

\section{Comparison of four ventilation and noise reduction designs}

Comparison of four ventilation and noise reduction designs is shown in Table 1 . In places with low noise requirements, the scheme of ventilation set in the outer wall or gates of the main transformer room can be used. In places with high noise requirements, intake mufflers must be used or ventilation through the interlayer of the lower cable layer of main transformer room could be used. Of the four kinds of ventilation schemes, the scheme of ventilation through the interlayer of the lower cable layer has the best cooling and noise reduction effects, with a moderate cost, which should be adopted when needed.

Table 1. Comparison of different ventilation and noise reduction systems

\begin{tabular}{|c|c|c|c|c|}
\hline NO. & Ventilation scheme & $\begin{array}{c}\text { Sound } \\
\text { transmission } \\
\text { loss }\end{array}$ & $\begin{array}{c}\text { Cooling } \\
\text { effect }\end{array}$ & Cost \\
\hline 1 & $\begin{array}{c}\text { Ventilation at the outer } \\
\text { wall of the main } \\
\text { transformer room }\end{array}$ & $<10 \mathrm{~dB}$ & good & low \\
\hline 2 & $\begin{array}{c}\text { Ventilation at the gates } \\
\text { of the main } \\
\text { transformer room }\end{array}$ & $<15 \mathrm{~dB}$ & fair & Low \\
\hline 3 & Intake muffler & $20-30 \mathrm{~dB}$ & good & High \\
\hline 4 & $\begin{array}{c}\text { ventilation through the } \\
\text { lower cable interlayer }\end{array}$ & $20-30 \mathrm{~dB}$ & $\begin{array}{c}\text { Very } \\
\text { good }\end{array}$ & Middle \\
\hline
\end{tabular}

\section{Conclusions}

(1)The ventilation cooling system design is not only for reasonable organization of the air flow to ensure that the appropriate ventilation rate, but also for noise reduction. (2)Different cooling schemes have different cooling and noise reduction effects, which should be adopted according to the practical needs. In places with low noise requirements, the scheme of ventilation set in the outer wall or gates of the main transformer room can be used. In places with high noise requirements, intake mufflers must be used or ventilation through the interlayer of the lower cable layer of main transformer room could be used (3)By comparing the four kinds of ventilation schemes, the scheme of ventilation through the interlayer of the lower cable layer has the best cooling and noise reduction effects with a moderate cost, which should be adopted when needed.

\section{References}

1. Jiang Chuan, Shandong power technology, 125, 3 (2002)

2. Jin Linfang, Power supply and consumption, 27,2 (2010)

3. Design code for $30 \sim 110 \mathrm{kV}$ substations (GB5005992)

4. Sun Yijian, Concise Ventilation Design Handbook.M, (1997) 